\title{
JĘZYKOZNAWSTWO
}

\section{КОММУНИКАЦИЯ В АСПЕКТЕ ГЕНДЕРНОЙ ЛИНГВИСТИКИ: ЖЕНСКИЙ СТИЛЬ СТЕРВЫ}

\author{
COMMUNICATION IN THE ASPECT OF GENDER LINGUISTICS: \\ STYLE OF THE BITCH
}

\author{
ТАТЬЯНА КОСМЕДА
}

\begin{abstract}
Aвstract. The article elucidates the problem of gender linguistics. The focus is on the feminine linguistics, one of women's speech styles, so called speech variety - 'style of the bitch'. The author specifies strategies and tactics of the actualized speech style which are expressed through modelling the speech genre of the praise, speech pattern of the coquette, tactics of the Ego and Alter Ego dialogue, types of verbal play etc. Besides, the semantic structure of the lexeme bitch is outlined to prove that its polysemy reflects enantiosemy and represents intraverbal evaluative antonymy and different stylistic signs resulting from different male and female perception of the world and different types of gender lingual consciousness.
\end{abstract}

Keywords: gender linguistics, feminine linguistics, speech strategies and tactics, speech genre of the praise, speech pattern of the coquette, gender types of lingual consciousness

Татьяна Космеда, Uniwersytet im. Adama Mickiewicza w Poznaniu, Poznań - Polska, tkosmeda@mail.com

ORCID ID: 0000-0001-8912-2888

Речевая деятельность, безусловно, отражает гендерные параметры, она гендерно маркирована, имеет систему гендерных стереотипов [см. Космеда, Карпенко, Осіпова, Саліонович, Халіман 2014].

Не считаем, однако, что есть основания противопоставлять «мужской» и «женский» языки как самостоятельные языковые и коммуникативные системы, хотя специфические стратегии и тактики языкового поведения мужчин и женщин, без сомнения, существуют, что фиксируется в гендерных коммуникативных мужских и женских компетенциях, дискурсивном пространстве. Условно все же можно выделять так называемые феминную и маскулинную лингвистики [Космеда 2016: 6].

Данное разыскание спроецировано на феминную лингвистику, постулаты которой активно разрабатываются современными учеными, в частности 
такими, как Михаил Алексеенко, Алла Архангельская, Елена Горошко, Оксана Забужко, Анна Кирилина, Оксана Кись и др.

Женщина, как доказывают психологи, думает обоими полушариями мозга, а мужчина, как правило, одним левым, что и объясняет, почему у женщин и мужчин по-разному организовано мышление, по-разному они чувствуют, воспринимают действительность и, что естественно, вербализуют ее. Женщины более мечтательны, более эмоциональны, доверяют интуиции, их настроение может быстро меняться, мужчины - логичны, серьезны, чувственны, менее подвержены влиянию настроения.

Одно и то же реальное событие или факт мужчины и женщины оценивают по-разному, что неоднократно иллюстрировалось примерами [Кон 1980: 25-36]. В качестве еще одного приведем распространенный анекдот. Мужчине и женщине задали один и тот же вопрос: „Какова вероятность того, что, выйдя на улицу, вы встретите динозавра?” Мужчина ответил, что шанс один из миллиона, а женщина - пятьдесят на пятьдесят. Когда женщину спросили, почему она так считает, то она сразу же, не задумываясь, объяснила: „Либо встречу, либо нет”.

Автор популярной публицистической книги для женщин Елена Шацкая осуществила попытку описать поведение успешной женщины, женщины, которая чрезвычайно привлекает мужчин, вызывает у них восторг. Для номинации последней она использует лексему стерва, подчеркивая, что значение этого слова, как и тип женщины, им именуемый, не обладает отрицательной коннотацией, а наоборот, - положительной. Стерва - это „женщина, которая находится на полюсах «домохозяйка» и «феминистка»", „«золотая середина»: между домохозяйкой и эмансипэ”, „королева”, „женщина загадка”, „мечта”, „райская птица”, „Двигатель человечества", „женщина с изюминкой”, „если она не красавица, то не дурнушка, нескучная в своей «некрасивости»"; „она может себе позволить некрасивую сексуальность и смелые туалеты". Стерва - это „немного информации, «кусочек» желания, «капелька» честолюбия, «щепотка» упорства и ЛЮБОВЬ (!!!) к мужчинам" [Шацкая 2007: 5].

Женское мнение Шацкой отражает противоречие в определении психологического типа стервы, ибо, с одной стороны, писательница считает, что „ключевое слово, применительно к стерве - эгоистка, женщина, которая живет ради себя и на пути к своему счастью, благосостоянию и удовольствию разбивает мужские сердца" [Шацкая 2007: 20], но, с другой стороны, „стерва не эгоистка, но и не альтруистка" [Шацкая 2007: 53].

Сильвия Чиз уверена, что „стервами не рождаются - ими становятся” [Шацкая 2007: 6], т.е. быть стервой - это умение, которое приобретается, 
вырабатывается, и выражается оно прежде всего в определенном вербальном стиле поведения.

Стерва, как представляется, слово с оценочно-обобщающим квалификативным типом значения [см. Космеда 2000]. Мужчины считают, что в семантическую структуру значения этого слова входят такие смыслы, как „огонь, вода и медные трубы, через которые нельзя пройти и остаться прежним”, „муза и разрушительница”, ,женщина-вамп”, „женщина-наркотик”, ,женщина-разлучница”, ,любовница" , „светская львица”, „, хищница”, „бестия”. А когда не могут доходчиво и подробно охарактеризовать подобный женский тип, обобщают - стерва.

Если разговор заходит о женщинах вышеописанного типа, как правило, в мнениях мужчин нет единства относительно объяснения, что такое стерва. Данный женский тип редко обсуждают в мужских компаниях. При этом, как считает Елена Шацкая, словарный запас для выражения восхищения и удовольствия „у большинства мужчин остался на пещерном уровне", ибо их оценки - это лишь словесные выражения, вербализующие исключительно их чувства и эмоции, ср.: „О!”, ,"Ух-ты!”, „Ну надо же!” или „Это было что-то!”. Неспособность выражения собственных эмоций и чувств удерживает мужчин от общения на эту тему даже друг с другом. Шацкая подчеркивает:

Существует подозрение, что универсальное слово «стерва» придумали именно мужчины, чтобы именно так называть женщин, которые описанию не поддаются. Стерва - это тайный мужской шифр, который может означать все, что угодно [Шацкая 2007: 19].

Таким образом, очевидно, в последнее время это слово перестало быть исключительно ругательством. Если женщину назвали стервой - значит, она „в чем-то кого-то переплюнула” [Шацкая 2007: 5] и ею восхищаются. Прагматика и семантика слова расширилась. Как представляется, значения лексемы стерва иллюстрируют явление энантиосемии - внутрисловной антонимии, в частности и с точки зрения категории оценки: это слово многозначно и имеет два значения, одно из которых отражает традиционную отрицательную коннотацию, относится к сфере бранных слов, а другое выражает скорей положительную оценку и восхищение, одобрение [см. Космеда 2000: 53].

В современных толковых словарях русского языка слово стерва описано следующим образом:

Стерва, ы; ж. Бранно. Подлый мерзкий человек (о женщине). Ну ты и с.! Не связывайся с этой стервой! Она порядочная с. > Стервоза (см.). Стервочка, -м; мн.; род. -чек; дат. -чкам; Смягчит. [БТСРЯ 2000: 1267]. 
Как видим, в словаре зафиксировано, что это слово имеет и уменьшительно-ласкательную форму, которая, по мнению составителей словаря, смягчает значение отрицательной оценки.

Очевидно, в толковых словарях необходимо отразить динамику, имеющую место в структуре значения этого слова, и зафиксировать также иное значение с пометами „с восхищением, одобрительно” 'о женщине, которая вызывает восхищение у мужчин, их одобрение, привлекает их внимание, умеет достигать своих целей любыми путями'.

Как показывает практика, наблюдения психологов, мужчина чувствует грань, за которой „начинается стерва”, и в его саркастически-возмущенных комментариях всегда присутствует доля восхищения, выраженная, например, в такой словесной форме: „Ай да стерва, ай да сукина дочь!”. Мужчины, по их мнению, знают, чего можно ожидать от стервы, а именно: измен и корысти, нелюбви, капризов и истерик. Мужчина даже считает, что стерве позволительны подобные слабости, ибо они включаются в предложенную ими игру [Шацкая 2007: 21].

Вербальное поведение стервы имеет свой стиль, стратегию и систему тактик, некоторые из которых определяются следующим образом:

1. Тактика молчания, суть которой в следующем: если ты ничем особенно не отличаешься - необходимо больше молчать и „напустить таинственности", что соответствует стандартным постулатам теории коммуникации. Ср. народную мудрость: слово - серебро, молчание - золото.

2. Тактика поведения, направленная на моделирование речевой стратегии и системы речевых тактик: если ты не можешь повлиять на обстоятельства, необходимо изменить их, например, устроить шоу или скандал, привлекая к себе внимание.

3. Форма речевого поведения: играть с окружающими людьми, „примеряя" различные „коммуникативные маски”, актуальные в каждой конкретной ситуации [Космеда, Халіман 2013]. При этом используются, например, такие фразы: „Сможешь ли ты, дорогой, стать лучше меня, чтобы я полюбила тебя больше, чем себя?". Мужчины, как считается, охотно принимают такой вызов, условия подобной игры и стремятся соответствовать выдвинутым требованиям, используя свои мужские коммуникативные стратегии и систему тактик, имеющихся в их арсенале.

Считается, что именно „игровое” коммуникативное поведение „стервы” привлекательно для мужчин, особенно мужчин талантливых и незаурядных, любящих игру, ибо появляется жизненная интрига, которая вызывает у них интерес, азарт охотника, свойственный психологии каждого мужчины.

Ученые-психологи выдвинули тезис, что так называемые „женщины-стервы" похожи на мужчин по складу ума, но при этом все-таки 
отличаются и от них, и от обычных женщин. Их поведение загадочно и непредсказуемо. А по законам философии противоположность привлекает, жизнь - это борьба противоположностей.

Среди вербальных игровых тактик стервы можно выделить следующие типы: а) имитация речи знакомых, друзей; б) моделирование акцентов, используемых часто и известными комиками. Шацкая дает по этому поводу некоторые рекомендации, например, она предлагает актуализировать одесско-еврейский говор либо копировать речь популярных комиков, например, современного украинского эстрадного артиста Андрея Данилко, который создал комичный образ Верки Сердючки. Ср. конкретные словесные формулы, предложенные Еленой Шацкой: „Скажи любимому вместо «Ты совсем дурак!» смешное «Чы шо ты 3 глузду зъихав?»" [Шацкая 2007: 74] и под.

4. Специфика направления диалога Ego и Alter Ego, т.е. внутреннего диалога, диалога про себя, из которого складывается картина мира, отражается отношение человека к окружению, действительности и себе. У стервы имеется собственная тактика защиты от мира. Она не дожидается, когда ее похвалят, - она сама себя хвалит. Например, для того, чтобы успокоиться, вселить в себя уверенность в собственных силах, своей уникальности, неотразимости и т. д., стерва произносит: „Ай да Я! Ай, да умница!”, „,Я лучше всех!”, „НИкто лучше меня этого не сделает!”; следом за ее чихом может последовать: „Будь здорова, дорогая, ты смотри у меня, не заболей!”; после неприятного разговора: „Не обращай внимания! Из этого ничего не следует. Все равно я прекрасна и неотразима во всем!”, а для поднятия настроения: „Посмотри, какой прекрасный день! Какое солнышко! Сколько вокруг интересного и приятного!" и под.

5. Коммуникативный жанр „похвалы себя любимой” распространяется как основная тактика и на диалоги с окружающими людьми. Ср.:

а) стерва может начать телефонный разговор со слов: „Я сегодня была молодец, поэтому хочу пригласить тебя на бутылочку вина". Таким образом, стерва считает, что не нужно ждать чужих, зачастую неискренних слов, если всегда можно вспомнить что-нибудь приятное и оценить по достоинству собственные заслуги или внешние данные и наградить себя за это;

б) у стервы своеобразная реакция и на комплименты от окружающих. Как считается, нормальная реакция на комплимент уверенной в себе женщины „стоит где-то посередине между пренебрежительным кивком, дескать, сами знаем, и восторженно-идиотским: «Да вы правда так думаете?»" или „отнекиванием" типа: „„ «Да нет, что вы, вам показалось, на самом деле...»” [Шацкая 2007: 53]. Стерва же в ответ на комплимент „Вы прекрасно выглядите!” отвечает примерно так: „Спасибо. Значит, мои старания не пропали даром”, или „Ой! Да это я еще себя чувствуя не самым лучшим 
образом!" На похвалу по поводу одежды или сопровождающего ее мужчины стерва может отреагировать, применяя тактику кокетки, например так: „Да, я и сама ничего!” или „А я уж думала, что в этой компании нет мужчин, умеющих вовремя и красиво сказать женщине правду!", либо „Говорят, что льстить - значит уметь сказать человеку то, что он сам о себе думает. Сударь, да вы льстец!”, или „Приятно слышать такие слова! Только не говорите мне об этом слишком часто, иначе я возгоржусь". После каждой из этих фраз, скорее всего, последует следующий комплимент, что и программирует такая женщина-коммуникатор;

в) стерва умеет видеть комплименты там, где их вовсе нет, считая „негативные коммуникативные речевые жанры” „скрытыми” комплиментами. Такое „видение” коммуникации, ее интерпретация или, точнее, самовнушение также поднимает настроение, самооценку. Например, на замечания или порицания мужчины-начальника стерва может реагировать абсолютно положительно, размышляя примерно так в своем внутреннем диалоге: „Если мужчина учит меня жить и стремится перевоспитать, значит, он ко мне неравнодушен и, вполне возможно, планирует предложить руку и сердце; очевидно, он так выражает свое особое внимание”, или „Директор, который постоянно придирается и задерживает на работе, давно бы плюнул или уволил, если бы я была действительно плохим работником. Значит, я ценный работник, которому «грозит» повышение. Просто это «скрытый» комплимент";

г) похвалу, предназначенную другим, стерва умеет адресовать и себе, хотя бы частично. Например, родители считают, что хвалить детей слишком много - это плохо, и такая похвала может разбаловать ребенка. В этом, как считают психологи, есть доля истины. Однако, когда мать говорит, например, что воспитала двух достойный членов общества, то здесь наблюдаем вербализацию речевой тактики стервы, ведь половину комплимента она адресует именно себе [Шацкая 2007: 54];

д) комплимент в виде лести стерва использует для реализации коммуникативной тактики „переключения стрелок”, ибо она знает: когда говоришь человеку, как он хорошо выглядит и вообще какой он молодец, он сразу переключается на себя, забывая о конструктивной критике в твой адрес. Стерва вообще любит говорить комплименты, ибо она убеждена, что умение признать, что кто-то сделал что-то хорошо - великое искусство, которым никогда не владеет слабый человек. Умение говорить удачные комплименты повышает коммуникативную компетенцию, имидж говорящего [см. Шкіцька 2012] и его значимость в обществе.

6. Стерва умеет нейтрализовать негатив, снять стресс, ее основная стратегия - направленность на положительную коммуникацию, оптимизм. Одна из тактик для достижения вышеназванного, кроме уже пере- 
численных - умение шутить, моделировать юмор, используя либо собственные высказывания, либо актуализируя чужие (прецедентные) тексты, что помогает легко воспринимать сложные жизненные ситуации. Стерва иронизирует над теми жизненными ситуациями, которые нельзя изменить, понимая, что к ним нужно просто приспособиться, например, когда возраст уже не радует, то можно себя успокоить: „Пересчитай свои годы на деньги, и ты увидишь, как это мало” [Шацкая 2007: 63], „Мое лицо - мое богатство" [Шацкая 2007: 135], или в ситуации беспричинной раздраженности: „Если б я знала, на что я так зла, я бы не была так зла” (Миньон Маклофлин) [Шацкая 2007: 76]. А огорчаясь набранными лишними килограммами, можно вспомнить цитату из книги Льюиса Кэролла Алиса $b$ стране чудес: „От уксуса - куксятся, ... от горчицы - огорчаются, от лука - лукавят, от вина - винятся, а от сдобы - добреют. Как жалко, что никто об этом не знает..." [Шацкая 2007: 76]. Таким образом, стерва умеет успокаивать себя, а для нейтрализации стресса у своих друзей она использует тактику лести, что имеет успех, ибо включается коммуникативный закон поглощения негативных эмоций.

7. Стерва старается ничем не выказывать своего превосходства в коммуникации, ибо знает: ничто так не подстегивает людскую зависть, как демонстрация своего превосходства. При этом она использует систему приемов: а) прием „отрицания успеха”, например, при условии хорошего заработка (чтобы никого не провоцировать на зависть) в разговоре необходимо несколько раз повторить, что „не в деньгах счастье”, пусть человек, у которого их нет, успокоится, считая, что, заработанное не принесло большого счастья; б) кроме этого, хорошо нейтрализует негатив ответная тактика под названием „мнимая зависть”, которую рекомендуется вербализовать, например, так: „Толку-то, что мой хорошо зарабатывает, у твоего руки-то золотые, а мой на гвоздь смотрит так, словно он с Марса прилетел"; в) еще один коммуникативный прием „напроситься «на пожалеть»": необходимо красочно рассказать о своих неудачах, горе, проблемах со здоровьем и о вечно придирающемся начальнике, тогда собеседнику, прежде всего женщине, будет легче узнать и перенести известие о том, что ты встретила свое счастье и собираешься замуж; г) прием „спиши свой успех на везение”, ибо каждому человеку в силу специфики его психологии гораздо легче поверить, что кому-то просто повезло, а ему нет, чем-то объяснить отсутствие собственных достижений. Для женщин-стерв „самый лучший способ борьбы с завистниками - общаться с ними поменьше”. Как отмечает Е. Шацкая, именно стервам принадлежат высказывания типа: „Зависть - двигатель прогресса” или „С детства во мне боролись две крайности - желание избавиться от завистников и желание, чтобы мне завидовали” [Шацкая 2007: 83]; 
8. Особенности невербального поведения женщины-стервы, которое, как известно, очень важно в моделировании и восприятии человеческой речи, также образно и ярко описала неоднократно цитируемая в этой статье Елена Шацкая. Приведём довольно прозрачное и, как представляется, не требующее комментирования высказывание:

Стерва - это, во-первых, воплощение дикой кошки в человеческом обличии, в которой каждый жест говорит о независимости, внутренней силе, красоте и предвкушении скорой добычи, а во-вторых, это нежная пушистая кошечка, которая будет мурлыкать, свернувшись на коленях, и покажет коготки только в самом крайнем случае [Шацкая 2007: 138].

Таким образом, в результате проведенного анализа можно сформулировать следующие выводы: (1) под влиянием экстралингвистических факторов, актуализированных действием гендерной политики, наблюдаем изменение лексического значения, что подтверждается и анализом семантических сдвигов, происходящих в структуре слова-феминизма стерва; (2) возникла необходимость отражения в словарных дефинициях современных толковых словарей разного „видения и восприятия мира” двумя противоположными гендерными типами языкового сознания, что, соответственно, наблюдается в гендерных стереотипах коммуникативного поведения - маскулинном и феминном; (3) разница в толковании отдельных лексико-семантических вариантов значения слова отражается в аксиологически противоположных типах значения: прослеживаем несовпадение оценочного характера коннотации, что может порождать гендерно мотивированную энантиосемию; (4) в системе женских языковых типов имеется основание выделить и тип женщины-стервы, для которого характерны: (а) специфические коммуникативные стратегии и тактики, рассчитанные на успех в общении как с мужчинами, так и с женщинами, (б) проявление своеобразного типа коммуникации, именуемого диалогом Ego и Alter Ego (автокоммуникация), основанного на стратегиях, тактиках и приемах позитивной коммуникации, порождающей позитивное мышление.

\section{Библиография}

Кон И. С. 1980. Психология половых различии, „Вопросы психологии”, № 2, с. 25-36.

Космеда Т. 2000. Аксіологічні аспекти прагмалінгвістики: формування і розвиток категоріі оцінки, Львів: ЛНУ імені Івана Франка.

Космеда Т. 2012. Ego і Alter Ego Тараса Шевченка в комунікативному просторі щоденникового дискурсу, Дрогобич: Коло. 
Космеда Т. 2016. Женский и мужской стили речи: особенности моделирования и прагматика (на материале художественного текста), [в:] J. Mampe, H. Makurat (ред.), Socjolingwistyczne badania w teorii i praktyce - ujęcie interdyscyplinarne, Gdańsk: Wydawnictwo Uniwersytetu Gdańskiego.

Космеда Т. А., Карпенко Н. А., Осіпова Т. Ф., Саліонович Л. М., Халіман О. В. 2014. Гендерна лінгвістика в Україні: історія, теоретичні засади, дискурсивна практика, за наук. ред. Т. А. Космеди, Дрогобич: Коло.

Космеда Т., Халіман О. 2013. Мовна гра в парадигмі інтерпретативної лінгвістики. Граматика оцинки. Граматична ігрема (теоретичне осмислення дискурсивної практики), Дрогобич: Коло.

Шацкая Е. 2007. Большая книга стервы. Полное пособие по стервологии, Москва: АСТ Астрель.

Шкіцька I. Ю. 2012. Маніпулятивні тактики позитиву: лінгвістичний аспект, за наук. ред. В. М. Бріцина, Київ: ВД Дмитра Бураго.

\section{Условные сокращения}

БТСРЯ - Кузнецов С. А. (ред.) 2000. Большой толковый словарь русского языка, Санкт-Петербург: Норинт. 
